\title{
Bases históricas para os modelos de programação das rádios universitárias públicas ${ }^{1}$
}

\author{
Nísio TEIXEIRA ${ }^{2}$ \\ Rafael MEDEIROS ${ }^{3}$
}

Resumo:

As rádios hertzianas vinculadas a universidades federais brasileiras constituem um universo representativo de 30 emissoras. Desde a criação da primeira rádio em uma universidade federal em 1957, essas emissoras têm o desafio de consolidar uma programação que incorpore suas configurações como emissoras públicas, educativas e universitárias. Como desdobramento de pesquisa que mapeou as características dos modelos de programação das rádios universitárias públicas, o trabalho busca verificar os movimentos de construção histórica da programação das rádios públicas educativas como matrizes da constituição da programação das rádios universitárias.

Palabras clave:

Rádios educativas. Rádios universitárias públicas. Programação radiofônica.

\section{Historical basis for the programming models of public university radios}

\begin{abstract}
:
Hertzian radios linked to Brazilian federal universities constitute a representative universe of 30 broadcasters. Since the creation of the first radio in a federal university, in 1957, these broadcasters have the challenge of consolidating a programming that incorporates their configurations as public, educational and university broadcasters. As a result of research that mapped the characteristics of the programming models of public university radios, the work seeks to verify the movements of historical construction of the programming of public educational radios as the matrix of the constitution of the programming of university radios.
\end{abstract}

Keywords:

Educational radios. Public university radios. Radio programming.

\section{Bases históricas para los modelos de programación de las radios universitarias públicas}

\begin{abstract}
Resumen:
Las radios hertzianas vinculadas a universidades federales brasileñas constituyen un universo representativo de 30 emisoras. Desde la creación de la primera radio en una universidad federal, en 1957, esas emisoras tienen el desafío de consolidar una programación que incorpore sus configuraciones como emisoras públicas, educativas y universitarias. Como desdoblamiento de investigación que mapeó las características de los modelos de programación de las radios universitarias públicas, el trabajo busca verificar los movimientos de construcción histórica de la programación de las radios públicas educativas como matrices de la constitución de la programación de las radios universitarias.
\end{abstract}

Palabras clave:

Radios educativas. Radios universitarias públicas. Programación radiofónica.

${ }^{1}$ Esta é uma versão revisada e ampliada do texto apresentado no GT de História da Mídia Sonora, integrante do V Encontro Regional Sudeste de História da Mídia - Alcar Sudeste 2018, em Belo Horizonte.

${ }^{2}$ Professor Adjunto vinculado ao Departamento de Comunicação Social da Faculdade de Filosofia e Ciências Humanas da Universidade Federal de Minas Gerais (UFMG). Doutor em Ciências da Informação pela UFMG. E-mail: nisiotei@gmail.com

3 Doutorando do Programa de Pós-Graduação em Comunicação da Universidade Federal de Santa Maria (UFSM). Mestre em Comunicação pela Universidade Federal de Ouro Preto (UFOP). E-mail: rfmedeiros13@gmail.com. 


\section{Introdução}

O presente trabalho se desdobra de uma pesquisa realizada com o objetivo de analisar a programação das rádios universitárias públicas considerando seus aspectos particularizantes, pensando os desafios das suas configurações como emissoras públicas, educativas e universitárias. A pesquisa também verifica como movimentos de construção histórica da programação das rádios públicas educativas contribuíram para a constituição da programação das rádios universitárias.

Existem algumas propostas de periodização e caracterização histórica da radiodifusão no Brasil. Por se tratar de uma periodização voltada para a trajetória do rádio público, o presente trabalho abarca a experiência de Zuculoto (2012) e propõe incluir de forma menos delimitada e mais abrangente as rádios universitárias nesse percurso histórico. Para investigar como as emissoras universitárias constituíram seus modelos de programação, foi feita uma revisão de bibliografia com base na historiografia das rádios educativas e universitárias, audição sistematizada e análise das grades de programação das rádios UFMG Educativa e UFOP Educativa.

O movimento de recuperação da história da radiodifusão educativa no Brasil proposto aqui tem em destaque aspectos que contribuíram para a configuração das programações das rádios universitárias. Assim, considerando as bases históricas do sistema brasileiro de radiodifusão, fundadas em uma programação de caráter educativo, a periodização histórica leva ao que se entende como um modelo de programação das rádios universitárias públicas, que engloba as características históricas dessas primeiras emissoras e inclui características próprias do espaço universitário.

\section{Periodização histórica do rádio educativo no Brasil}

A radiodifusão pública brasileira teve suas raízes em um sistema educativo de programação. Segundo Zuculoto (2012), nos anos de implementação do rádio no Brasil, as emissoras pioneiras já tinham uma visão de que a radiodifusão deveria ser propagadora de educação e cultura. Considerada a primeira emissora brasileira, a Rádio Sociedade do Rio de Janeiro foi fundada por Edgar Roquette-Pinto e Henrique Morize, em 1923, para ser um canal voltado para a educação, ciência e arte.

Apesar das intenções daquele que é considerado o patrono do rádio no Brasil, as emissoras nasceram com programações elitizadas que atingiam uma minoria da população que tinha dinheiro para comprar os receptores e com uma estrutura física bastante frágil. 
Outro ponto que levava a esses dois aspectos levantados era a própria organização das emissoras, que, tidas como clubes, sociedades ou agremiações, funcionavam com a contribuição financeira dos associados e ouvintes.

No estudo de Zuculoto (2012), o resgate histórico da radiodifusão pública é feito em uma periodização constituída de cinco fases. A primeira fase compreende os anos que vão da década de 1920 ao início da década de 1940, atentando para as condições de surgimento do rádio no Brasil de maneira geral, com claras intenções de transmitir educação e cultura. Como citado anteriormente, a Rádio Sociedade do Rio de Janeiro foi criada sob tais expectativas em 1923, e, quando doada por Roquette-Pinto ao Ministério da Educação e Cultura, em 1936, oficializou o surgimento de um sistema educativo de rádio (MOREIRA, 1991, p. 17). Por mais que a proposta da presente pesquisa enfoque nas rádios públicas universitárias, é importante essa ênfase dada à Rádio Sociedade como resgate histórico das bases de programação das rádios públicas educativas, por servir de referência para as demais emissoras pioneiras e também porque

[...] os objetivos do rádio educativo pioneiro continuam a referenciar linhas editoriais das emissoras públicas na atualidade. Outras demonstrações contundentes de que o rádio pioneiro irradiou matrizes e referências estão na programação da Rádio Sociedade (ZUCULOTO, 2012, p. 93).

De acordo com Andrelo e Donini (2017, p. 194-195), desde o começo a Rádio Sociedade se voltou para "uma perspectiva mais popular de educação, [veiculando] aulas de francês, português, geografia, história do Brasil, higiene, silvicultura, química, história natural e física, além de transmissões de concertos e espetáculos teatrais" e programação musical essencialmente erudita. Sobre as aulas, Milanez (2007, p. 24-25) destaca que "o conteúdo e a escolha dos professores demonstravam preocupação com a qualidade do que era veiculado" e que os conteúdos técnicos eram simplificados para que pudessem ser entendidos pelos ouvintes.

A partir da doação da Rádio Sociedade do Rio de Janeiro por Roquette-Pinto ao Ministério da Educação e Cultura, a emissora passou a se se denominar Rádio MEC e o governo começou a tomar iniciativas de educação formal por meio do rádio. Conforme evidencia Neuberger (2012), a transformação da Rádio Sociedade em Rádio MEC “levou à criação do SRE - Serviço de Radiodifusão Educativa, por meio da Lei no 378, de 1937, que buscava o norteamento do rádio como auxílio à educação e ao ensino, através da irradiação de programas científicos, literários e artísticos de caráter educativo" (NEUBERGER, 2012, p. 89). 
A segunda fase da radiodifusão pública descrita por Zuculoto (2012) se concentra entre meados dos anos 1940 e o começo da década de 1970 e coloca em evidência justamente o desenvolvimento das experiências de educação formal pelo rádio, além de outras propostas de educação informal e o surgimento de projetos governamentais, por meio do SRE, para consolidar o rádio como canal de aprendizado.

O começo desse momento é marcado pela chamada "era de ouro" da radiodifusão comercial: quando o rádio passou a ficar mais acessível e popular, surgiram muitas emissoras novas impulsionadas por patrocinadores e com programações marcadas por grandes espetáculos, radionovelas e programas jornalísticos. Nesse contexto, conforme aponta Aguiar (2007, p. 16-17), a PRE-8 Sociedade Rádio Nacional foi inaugurada em 12 de setembro de 1936 e incorporada ao governo no dia 8 de março de 1940 por meio do Decreto-Lei $n^{\circ}$ 2073, assinado pelo então presidente Getúlio Vargas. Segundo o autor (2007), a incorporação teve claros objetivos de influenciar a formação de uma identidade nacional por meio da veiculação de programação diversificada e popular que incluía grandes programas de auditório, radionovelas, musicais, humorísticos e jornalísticos, como o Repórter Esso. É importante ponderar que mesmo anexada à União, portanto se tornando estatal, a Rádio Nacional afastou-se da filosofia do rádio educativo, estabeleceu os modelos de programação que foram seguidos pelas rádios comerciais da época e exerceu influência, embora restrita, até mesmo sobre as emissoras do segmento público.

A partir desse período, fica mais clara a possibilidade de diferenciar os caminhos tomados pelas programações das emissoras comerciais e não comerciais. As rádios começam a se posicionar em um desses sistemas mais a partir das suas programações que propriamente das suas vinculações institucionais. Um exemplo disso é a Rádio Inconfidência de Belo Horizonte, que, embora vinculada ao Governo do Estado de Minas Gerais desde sua fundação em 1936, passa a se desenvolver a partir de uma programação baseada nos moldes das rádios comerciais, sobretudo da Rádio Nacional do Rio de Janeiro (PRATA, 2010). “A popularização da programação da Inconfidência veio com o sucesso da Rádio Nacional. Tudo o que a Rádio Nacional fazia, o Brasil inteiro copiava e com a Inconfidência não foi diferente" (PRATA, 2010, p. 143).

Enquanto as rádios comerciais popularizaram suas programações em busca de ouvintes e publicidade, as rádios educativas tentaram consolidar uma posição alternativa às programações das emissoras comerciais, buscando manter as características pioneiras da radiodifusão educativa e expandir a transmissão de programas de educação não formal e 
outros tantos de ensino formal, muito sob a influência das ações do governo para essas iniciativas.

Nos meados da década de 1940 a Rádio MEC empenhou-se em fortalecer sua programação cultural e educativa por meio de mudanças na grade, o incremento de programas de MPB, além da música erudita preponderante no início, de programas artísticos, literários e séries produzidas por instituições parceiras, como o Colégio Pedro II, a Academia Brasileira de Letras e o Conselho Nacional de Pesquisa (ANDRELO; DONINI, 2017, p. 196).

Conforme destaca Neuberger (2012, p. 89), em 1944 o Serviço de Radiodifusão Educativa delineou as especificidades e distinguiu os tipos de programação educativa e instrutiva, considerando o rádio instrutivo como aquele que era destinado a transmitir cursos. De acordo com Pimentel (2009, p. 38), "o rádio instrutivo ficava a cargo do SRE, que inicialmente passou a realizar cursos de Português, Inglês e Geografia, com duas aulas semanais, transmitidas regularmente pela Rádio Ministério da Educação e Cultura".

A experiência de educação formal na emissora ganhou força com a veiculação da série Colégio no Ar, produzida pelo SRE e veiculada durante anos com conteúdos de cursos diversos. Zuculoto (2012, p. 125) aponta que "até mesmo aulas de Educação Física eram ministradas. Na MEC, estas aulas se chamavam Hora da Ginástica, programa também veiculado através de outras emissoras de São Paulo e do Rio de Janeiro".

No final da década de 1960 e início dos anos 1970 outras experiências de educação pelo rádio foram desenvolvidas sob iniciativa ou apoio do MEC, mas a grande aposta do SRE para consolidar o sistema de educação formal pelo rádio foi o Projeto Minerva, que teve sua transmissão inaugural em 04 de outubro de 1970 e marca o início de uma nova fase na periodização histórica da radiodifusão educativa. Essa nova fase é observada por Zuculoto (2012) como a consolidação das experiências de educação formal pelo rádio e de um modelo de programação que vinha sendo constituído desde o advento do rádio educativo. Após o golpe de 1964, o governo militar viu nos projetos de educação por meio do rádio uma forma de divulgar suas ideias e influenciar a opinião pública. Conforme descreve Pimentel (2009, p. 65), “o rádio educativo brasileiro passaria por uma fase de grandes investimentos - o que não corresponderia a resultados muito favoráveis -, tornando-se voz oficial da política de desenvolvimento do regime militar".

Os programas do Projeto Minerva eram compostos das aulas, unidades substanciais do curso, mas também pelos Informativos Culturais, que eram menos preocupados com a 
qualificação dos alunos e transmitiam informações sobre conhecimentos gerais. Segundo Pimentel (2009, p. 76), “cada série tratava de temas específicos, que, em conjunto, iriam compor um panorama cultural bastante amplo, dando maior espaço para as diferentes manifestações de cada região". O autor ainda evidencia que esses programas foram "um dos pontos mais positivos de todo o Projeto Minerva", chegando a superar alguns índices de audiência de emissoras já consolidadas (PIMENTEL, 2009, p. 68).

A partir desses pontos levantados, é possível perceber que o Minerva se destaca pela sistematização do processo de aprendizado à distância via rádio e pelos ganhos sociais, apresentando pontos positivos na consolidação do modelo de rádio educativo. Mas cabe notar que as bases de programação que compõem o projeto já vinham sendo executadas em outras experiências isoladas das rádios educativas, como cursos não sistematizados, programação cultural e projetos de divulgação científica.

Embora a importância da educação formal fosse relevante para essa fase do rádio educativo, o período que Zuculoto (2012, p. 141) considera como verdadeiramente a "época de ouro" do rádio não comercial acontece com o estabelecimento de redes de produções e transmissões conjuntas entre as emissoras educativas. Essas já somavam dezenas em todo o país na década de 1980, quando se reuniram em uma iniciativa chamada de Sistema Nacional de Radiodifusão Educativa (SINRED).

Após as experiências com os projetos governamentais de educação formal, as emissoras sentiram necessidade de serem mais independentes, de realmente se posicionarem como públicas, evidenciando suas programações de interesse público e não apenas por meio de suas vinculações institucionais. Conforme destaca Zuculoto (2012, p. 142), “[as educativas] pareciam vislumbrar a necessidade de ter um perfil nacional para emissoras da sua natureza, que só poderia se consolidar em atuação conjunta via produção e grade de programação" e o SINRED, apesar de criado sob a tutela governamental, "acabou sendo usado pelas emissoras para tentarem trilhar um caminho de programação que traduzisse melhor - e de forma mais autônoma e descentralizada - sua missão educativa [...]” (ZUCULOTO, 2012, p. 142).

Para Blois (2004, p. 165-166), a programação definida pelas emissoras do SINRED era "um retrato vivo da cultura brasileira sendo levado, via rádio, aos brasileiros", já que o conteúdo era voltado para as especificidades das regiões brasileiras e transmitido por emissoras educativas de todo o país. O SINRED foi iniciado de maneira oficial em 1983, funcionou até 1988 e deixou um legado que vai além do intercâmbio de conteúdos. A 
iniciativa possibilitou a troca recíproca de modelos de programação e produção no momento em que o número de emissoras educativas era crescente, sobretudo com os canais em frequência modulada (FM).

Embora as rádios comerciais tenham se desenvolvido nos canais FM a partir dos anos 1970, as rádios educativas efetivamente se expandiram na frequência a partir dos anos 1980. É esse momento destacado por Zuculoto (2012) na quarta fase da radiodifusão educativa no Brasil, com o aumento do número de emissoras educativas em FM e a delineação de um modelo de programação direcionado mais amplamente para a educação.

O desenvolvimento dos canais FM se deu a partir de ações governamentais para a extensão dos meios de comunicação, mesmo que por interesses e ideais ligados a metas políticas e econômicas do governo militar. Uma dessas ações foi a publicação, em 1977, do Plano de Distribuição de canais educativos e comerciais em FM, com a reserva de 350 canais para a educação (ZUCULOTO, 2012), o que impactaria diretamente na criação de emissoras universitárias na década de 1980, como pode ser observado na Figura 1. Segundo dados da pesquisa de Blois (1996) ${ }^{4}$, citados por Zuculoto (2012), as emissoras educativas que operavam em FM tiveram um crescimento de $225 \%$, algo considerado pouco significativo perto da expansão das emissoras comerciais, mas que, segundo a autora, gerou transformações no grupo de rádios por ela pesquisado que "podem ser ressaltadas como principais influências dos rumos das suas programações" (ZUCULOTO, 2012, p. 166).

Outro ponto resgatado por Zuculoto (2012) que se destaca nessa fase é a iniciativa da Rede Universitária de Rádios, importante projeto de construção coletiva de programação e de divulgação científica, um dos pilares da programação das rádios universitárias. A Rede surgiu da constatação de que as emissoras vinculadas a universidades precisavam demarcar suas características, buscar uma identidade comum e, assim, reforçar um lugar próprio no sistema de radiodifusão nacional.

Nesse cenário, a Rádio MEC promoveu em março de 1994 o I Encontro Nacional de Rádios Educativas e Universitárias, de onde saiu a proposta da criação de uma Rede Nacional de Emissoras de Rádio Educativas e Universitárias. A proposta não foi levada adiante, mas "a disposição de concretizar este tipo de produção em cadeia e horizontalizada - com todos não só retransmitindo, mas também participando da produção

\footnotetext{
${ }^{4}$ BLOIS, Marlene. Florescem as FM Educativas no Brasil. Radiografia do radioeducativo no Brasil e os fatores favoráveis à ocupação dos canais de FM educativos. 1996. 471 fl. Tese (Livre Docência em Comunicação - Televisão e Rádio) - Universidade Gama Filho, Rio de Janeiro, 1996.
} 
e veiculação - avançou rapidamente" (ZUCULOTO, 2012, p. 170).

Em maio de 1994, em um novo encontro, dessa vez, realizado em Florianópolis, Santa Catarina, as emissoras definiram que a primeira formação da Rede Universitária de Rádios aconteceria para a cobertura da Reunião Anual da Sociedade Brasileira para o Progresso da Ciência (SBPC) em Vitória, Espírito Santo. Assim, em julho de 1994, a Rede Universitária se formou pela primeira vez. A produção conjunta da cobertura da $46^{\mathrm{a}}$ Reunião Anual da SBPC contou com professores, profissionais e estudantes representantes das emissoras da Rede, que transmitiu programas de hora em hora trazendo o cenário do encontro. A Rede se reuniu mais seis vezes para a cobertura das reuniões anuais da SBPC, aumentando ano a ano o número de emissoras em rede nas transmissões, chegando a aproximadamente 200 na última cobertura dessa fase, realizada em 2002 durante a $54^{\mathrm{a}}$ Reunião Anual da SBPC, em Goiânia. De acordo com Zuculoto (1996, p. 13), "a rede tentava, democraticamente, transmitir e disseminar o conhecimento que tem ficado restrito aos pesquisadores, estudiosos e ao meio acadêmico".

Como é possível verificar ao longo dessa periodização, as rádios públicas sempre estiveram buscando definir seu lugar e seu papel no universo da radiodifusão brasileira. Nessa fase que chega com o século XXI, Zuculoto (2012) atenta que as definições do caráter público das emissoras não comerciais seguem sendo construídas a partir da programação que elas veiculam e não apenas pela vinculação institucional: é por meio da programação que essas rádios buscam se autoproclamar públicas.

Em setembro de 2017, durante a realização do Fórum de Rádios e TVs Universitárias, em Curitiba, Paraná, foi lançado um manifesto pela criação da Rede de Rádios Universitárias do Brasil, com o objetivo de reunir as diferentes iniciativas de radiodifusão universitária no país, sejam rádios $\mathrm{AM}$ e $\mathrm{FM}$, núcleos de produção laboratorial radiofônica ou web rádios vinculadas a instituições de ensino superior. Entre os objetivos dessa nova iniciativa de constituição de uma rede de cooperação entre as rádios universitárias estão:

Contribuir para a divulgação científica e tecnológica e para a universalização da educação, da cultura e do conhecimento produzido no âmbito universitário; [...] Oferecer aos estudantes universitários um espaço de troca que contribua para dinamizar o processo de ensinoaprendizagem em mídia sonora, fomentando a liberdade de expressão dentro dos princípios de responsabilidade social; [...] Promover a diversidade de vozes e atuar de forma inclusiva em defesa das minorias étnicas, culturais, religiosas e de gênero. (REDE DE RÁDIOS UNIVERSITÁRIAS DO BRASIL, 2017) 
Com uma legislação para comunicações ainda muito antiga e que não acompanha as tantas modificações das mais diversas ordens que os meios passaram, crescem as discussões acerca de um novo marco regulatório para o setor e os debates para o estabelecimento de um sistema público de rádio.

Imbuídos em um esforço de definição do caráter público nas emissoras não-comerciais brasileiras, entidades de movimentos organizados pela democratização da comunicação e de entes do campo público realizaram debates considerados marcos para a comunicação no país. (GUERREIRO, 2016, p. 45)

Cabe citar algumas iniciativas de debate dessas questões ligadas à comunicação pública de maneira geral e, especificamente, à radiodifusão: os Fóruns de TVs públicas, realizados em 2006 e 2009; o I Fórum Nacional de Rádios Públicas, em 2007; o III Encontro Nacional de Rádios Públicas, em 2009; a Conferência Nacional de Comunicação, também em 2009; e o Fórum de Comunicação Pública, ocorrido em 2014.

Segundo Guerreiro (2016, p. 46), “como resultado desses debates, produziram-se documentos que se propuseram a buscar entendimentos sobre a radiodifusão pública de forma mais aprofundada". Alguns pontos específicos importantes para o argumento acerca do caráter público das emissoras não comerciais despontaram a partir desses debates, especialmente no entendimento de que a vinculação institucional dessas emissoras não deve ser definidora de suas programações ou diretrizes de conteúdo.

Entre essas discussões, o governo federal instituiu a Empresa Brasil de Comunicação (EBC) em 2007, substituindo a Radiobrás ${ }^{5}$, sob o argumento de construir o sistema público de comunicação nacional. Inicialmente, a entidade foi formada pela TV Brasil e por uma Superintendência de Rádio e hoje é gestora da TV Brasil, TV Brasil Internacional, Agência Brasil, Radioagência Nacional, da emissora governamental TV Nacional do Brasil (NBR) e do chamado Sistema Público de Rádio, composto por oito emissoras $^{6}$, além de controlar outras doze emissoras federais ligadas a ela por convênios.

A estrutura institucional da EBC foi formada por órgãos da Administração (Conselho de Administração e Diretoria Executiva) e órgãos de Fiscalização (Conselho Curador, Conselho Fiscal e Auditoria Interna). Cabe destacar as responsabilidades de atuação e importância do Conselho Curador por

fiscalizar o cumprimento do caráter público, a partir de um

\footnotetext{
5 “A Radiobrás foi uma empresa pública do Governo Federal criada em 1975 para gerir todas as emissoras de TV e rádio do governo federal espalhadas pelo Brasil.” (COUTINHO; VIEIRA; CHAVES, 2014, p. 8).

${ }^{6}$ Rádio Nacional FM, Rádio Nacional de Brasília, Rádio Nacional do Rio de Janeiro, Rádio Nacional da Amazônia, Rádio Nacional do Alto Solimões, Rádio MEC FM, Rádio MEC AM Brasília e Rádio MEC.
} 
acompanhamento da programação e do conteúdo veiculado pelos canais da EBC. Além disso, ele se configurava como o principal espaço de participação da sociedade civil no âmbito da empresa. Essa participação é, inclusive, um dos principais diferenciais do modelo público em relação ao comercial e ao governamental. (VIEIRA; COUTINHO, 2016, p.188)

Apesar do importante papel que representava para a manutenção do caráter público da EBC e das emissoras por ela geridas e a ela conveniadas ou afiliadas, o Conselho Curador foi extinto pelo Governo Federal por meio da Medida Provisória no 744/16, publicada pelo então presidente Michel Temer no dia primeiro de setembro de 2016 e ratificada pela Lei $\mathrm{n}^{\mathrm{o}}$ 13.417, publicada em dois de março de 2017. O fim do Conselho Curador suprimiu a autonomia da EBC, o que pode ser visto como a retirada do caráter público da entidade e até mesmo como uma guinada para tornar as emissoras públicas ligadas a ela em governamentais e instrumentos de propaganda oficial, descaracterizando seu papel. A inferência foi confirmada no dia 10 de abril de 2019 com a junção das programações da TV Brasil e da NBR (canal oficial do Governo Federal), transformando a EBC, oficialmente, em órgão de propaganda oficial e instrumento de divulgação política.

As emissoras universitárias buscam se adaptar a essas mudanças contextuais no cenário da comunicação pública brasileira e também às contínuas mudanças internas, já que estão inseridas em um ambiente de constante convergência e hibridismo. Ao mesmo tempo essas rádios mantêm vinculação próxima às matrizes que determinaram suas programações e que estão presentes nessa periodização.

\section{De 1957 a 2017 - A construção histórica das rádios universitárias federais}

A Rádio da Universidade Federal do Rio Grande do Sul (UFRGS) foi a primeira emissora universitária do Brasil, funcionando de maneira amadora desde 1950 e oficialmente inaugurada em 18 de novembro de 1957, com licença definitiva para operar a frequência AM $1080 \mathrm{kHz}$ (RÁDIO DA UNIVERSIDADE, s.d.). Conforme rememora Sandra de Deus (2005, p. 94), "iniciava na radiofonia brasileira uma emissora dedicada exclusivamente a programas de cunho educativo, cultural e sem fins lucrativos". No começo, a Rádio da Universidade foi pensada para servir de laboratório para atividades didáticas e na sua matriz de programação, ainda como amadora, eram transmitidos boletins astronômicos, palestras e informativos sobre atividades acadêmicas; as irradiações de música (especificamente erudita) e programas recreativos começaram anos depois (RÁDIO DA UNIVERSIDADE, s.d.).

É possível verificar que a constituição da programação da primeira rádio 
universitária do país seguiu as matrizes já experimentadas pelas rádios educativas pioneiras, mas que a essas experiências se acrescentaram particularidades vindas de sua própria vinculação, seja como emissora-laboratório ou como emissora do conhecimento produzido na Universidade.

Para cumprir com o que se entende ser a função das rádios universitárias, a Rádio da Universidade possui uma programação heterogênea. A grade é preenchida com programas que divulgam tanto a produção de professores, alunos e de unidades acadêmicas da universidade, como também está aberta para todas as manifestações da comunidade. (DEUS, 2005, p. 94)

Essa citação da ex-diretora da emissora deixa claro o estabelecimento de um modelo de programação preocupado com as funções próprias da rádio universitária como veiculadora de educação e cultura, como divulgadora do conhecimento produzido na academia, mas também com a função social que é própria da universidade pública e da rádio pública, de compromisso com a comunidade.

A programação de outra pioneira entre as emissoras universitárias, a Rádio da Universidade Federal de Goiás, começou com características e missões parecidas com as da Rádio da UFRGS. Segundo Kossa (2010), a Rádio Universitária da UFG foi inaugurada em 1962, ano em que o governo começou a considerar a diferenciação entre FMs educativas e comerciais. Assim, a Rádio da UFG foi a primeira universitária com a outorga específica de rádio educativa. A emissora foi criada com intenção de ser uma divulgadora da Universidade, para que assumisse um papel institucional, mas também deixava claros os seus compromissos com as missões e bases históricas de programação das rádios educativas (KOSSA, 2010). O autor cita um trecho da resolução de criação da emissora, que evidencia esses objetivos:

Através da Resolução 14/62, a rádio deveria levar educação ao povo, visando o seu aprimoramento no que tange a noções de política social, higiene, puericultura, ciências, alfabetização primária e despertar de aptidão vocacional. A rádio deve também divulgar eventos culturais e educacionais que, antes da sua criação, são publicados na imprensa privada, o que onera a universidade. (KOSSA, 2010, p. 73)

Outro ponto importante verificado nas rádios universitárias pioneiras envolve aspectos referentes aos modelos de produção de conteúdo e o papel que muitas emissoras até hoje desempenham, de servir como laboratório de formação complementar para os alunos das universidades. Nas décadas que se seguiram, as rádios universitárias se expandiram aos poucos, na medida em que ações eram tomadas para incremento do FM e das iniciativas para educação por meio do rádio. Como pode ser verificado na Figura 1, no 
fim da década de 1980 as rádios ligadas a universidades federais constituíam um universo de 14 emissoras, distribuídas por sete estados brasileiros.

Figura 1 - Linha do tempo de criação das rádios universitárias federais no Brasil ${ }^{7}$

\section{LINHA DO TEMPO - Criação das rádios universitárias federais}

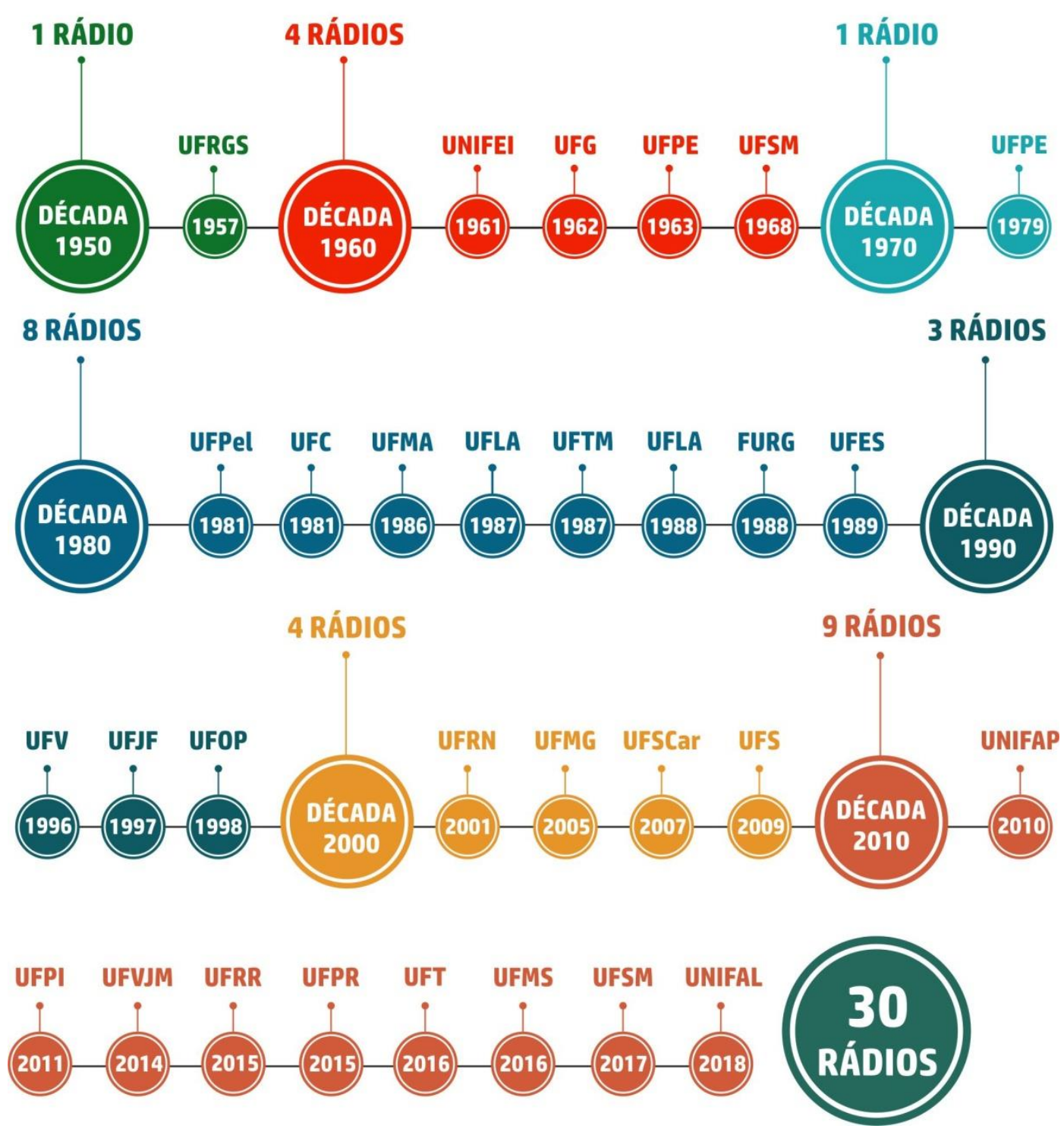

Fonte: Elaborada pelos autores com dados da pesquisa (2019).

É possível perceber a partir dessa linha do tempo que houve um importante ganho no número das rádios vinculadas a universidades federais na década de 1980, motivado pelo Plano de Distribuição de canais educativos e comerciais em FM, e a partir dos anos 2000, fato que pode ser explicado pelas ações do Governo Federal entre 2003 e 2016 para

\footnotetext{
${ }^{7}$ Dados coletados em 24 de maio de 2019.
} 
expandir as rádios educativas e universitárias. Entre esses direcionamentos estão a criação da EBC, que é detentora da concessão de algumas rádios geridas por universidades ${ }^{8} \mathrm{e}$ a prioridade da outorga de canais educativos para universidades públicas. Uma das metas que consta no Plano Plurianual (PPA) do Governo Federal em vigor entre 2016 e 2019 objetiva a criação de pelo menos uma rádio ou TV educativa em $90 \%$ dos municípios que têm universidades públicas (BRASIL, 2016).

As rádios universitárias mais recentes seguem tendo a noção do seu papel como emissoras educativas de caráter público e, particularmente, como emissoras vinculadas a universidades públicas. Inaugurada em 2016, uma das mais novas rádios públicas universitárias do país, a Rádio da Universidade Federal do Tocantins (UFT FM) deixa expresso o compromisso e a preocupação com uma programação de caráter público e o entendimento de seu papel particularizado como emissora vinculada a uma universidade pública. As diretrizes da Rádio UFT FM (MULLER, 2017, p. 4-5) trazem tópicos que contemplam o "incentivo à cultura e à produção local", a "diversidade e qualidade educacional da programação musical", a "disseminação do conhecimento produzido e armazenado na Universidade", entre outros:

O caráter público da UFT FM, aliado ao ambiente universitário na qual ela se encontra e a abertura à comunidade, faz da Rádio uma ferramenta importante para ampliar os horizontes do ouvinte tocantinense, musical e culturalmente, e que essa particularidade não pode ser desperdiçada. Portanto, a UFT FM deve atuar como uma alternativa à programação de rádio comercial, seja na música, seja no formato de seus programas. (MULLER, 2017, p. 4)

Apesar das modificações observadas ao longo da história da radiodifusão educativa de maneira geral, é possível afirmar que as emissoras universitárias têm definidos desde o começo seus objetivos e constituem suas grades de programação com bases nas características já experimentadas, acrescidas de suas próprias missões. A partir da periodização histórica apontada anteriormente e do levantamento das características das emissoras universitárias pioneiras, fica evidente também um caminho histórico que veio sendo traçado para que as programações das universitárias fossem constituídas tal como são atualmente.

\section{Considerações finais}

O olhar histórico, com base na pesquisa de Zuculoto (2012), permitiu caminhar

\footnotetext{
${ }^{8}$ Entre essas emissoras estão rádios da UFMG, UFPI, UFS, UFSM, UFRR e UNIFAP.
} 
pelos diversos movimentos de matrizes e modelos de programação, suas imbricações com os diferentes agentes influenciadores e evidenciar a construção desses modelos em diferentes formatos de emissoras públicas até chegar especificamente nas formas de composição das programações das emissoras universitárias.

A partir do levantamento histórico com foco na programação das emissoras educativas foi possível detectar que as bases de programação dessas emissoras têm suas raízes nas características das rádios pioneiras e nas influências da concepção das funções sociais do rádio cunhadas por Roquette-Pinto, já que a radiodifusão brasileira surgiu, por definição, como educativa. Ainda assim as rádios incluídas nesse grupo seguem buscando um modelo público e autônomo de gestão e programação que se adaptem às suas funções culturais, educativas e de caráter público.

Ao longo desse percurso histórico, a programação das emissoras públicas esteve em constante formação e busca por identidade, uma vez que os tempos de emissão precisam acompanhar os tempos sociais na configuração de modelos que caracterizam o interesse público dos seus conteúdos. As bases de programação das emissoras pioneiras ainda constituem elos fortes para o que temos como programação cultural e educativa das emissoras públicas atualmente.

Assim, é possível observar que, desde o surgimento da primeira rádio vinculada a uma universidade federal, a programação das emissoras universitárias vem se reconfigurando e buscando eixos comuns em seus modelos de programação e de produção de conteúdo. As características próprias da universidade e todas as variantes que circundam esse espaço determinam uma diferenciação dessas emissoras quando comparadas a outros canais considerados pela legislação como públicos e educativos.

Um desafio que se apresenta à pesquisa é vislumbrar os próximos passos da radiodifusão universitária no momento atual de instabilidade da comunicação pública brasileira. As emissoras parecem buscar um modelo de programação comum e uma integração mais abrangente a partir da formação de redes e retransmissão de conteúdos. Além disso, o aumento no número de emissoras e as possibilidades de surgimento de novas rádios em universidades públicas fazem com que o momento atual se mostre bastante particular, representando um esforço para futuras investigações a partir desse panorama atual. Seria essa a sexta fase da radiodifusão educativa?

\section{Referências}

AGUIAR, Ronaldo Conde. Almanaque da Rádio Nacional. Rio de Janeiro: Casa da 
Palavra, 2007.

ANDRELO, Roseane; DONINI, Adriana M. A trajetória do conteúdo educativo na Rádio MEC do Rio de Janeiro. In: DEL BIANCO, Nélia; KLÖCKNER, Luciano; FERRARETTO, Luiz Artur. 80 anos das rádios Nacional e MEC. Porto Alegre: EDIPUCRS, 2017. p. 193-211. Disponível em: http://ebooks.pucrs.br/edipucrs/Ebooks/Pdf/978-85-397-1027-0.pdf. Acesso em: 26 maio 2019.

BLOIS, Marlene M. Rádio educativo: uma escola de vida e de cidadania. In: BARBOSA FILHO, André; PIOVESAN, Ângelo; BENETON, Rosana (org.). Rádio: sintonia do futuro. São Paulo: Paulinas, 2004. p. 147-176.

BRASIL. Plano Plurianual 2016/2019. Volume II. Anexos. Disponível em: http://www.planejamento.gov.br/secretarias/upload/arquivo/spi-1/ppa-2016-

2019/rel_anual_de_avaliacao_ppa_2016_2019_volume_ii_anexos.pdf. Acesso em: 15 nov. 2017.

COUTINHO, Iluska Maria da Silva; VIEIRA, Allana Meirelles; CHAVES, Roberta Braga. A imagem construída sobre a TV Brasil: uma análise do discurso feito pela grande mídia brasileira sobre a televisão pública do país. Rumores, São Paulo, v. 8, n. 16, p. 4-18, jul./dez. 2014.

Disponível

em: http://www.revistas.usp.br/Rumores/article/view/89635/92448. Acesso em: 26 maio 2019.

DEUS, Sandra de Fatima Batista de. O papel das rádios universitárias públicas na extensão universitária. In: CONGRESSO IBERO-AMERICANO DE EXTENSÃO UNIVERSITÁRIA, 8., 2005, Rio de Janeiro. Navegar é preciso... transformar é possível. Rio de Janeiro: Universidade Federal do Rio de Janeiro, 2005. p. 91-96. Disponível em: https://lume.ufrgs.br/handle/10183/26678. Acesso em: 25 maio 2019.

EBC (Empresa Brasil de Comunicação). Moção de repúdio contra medida provisória que desmonta a EBC. [Brasília?], 02 set. 2016. Disponível em: http://www.ebc.com.br/institucional/conselho-curador/noticias/2016/09/mocao-de-repudiocontra-medida-provisoria-que-desmonta-a-ebc. Acesso em: 10 maio 2018.

GUERREIRO, Soane Costa. TV Brasil e a Rede Pública de Televisão: uma trajetória de dependência. 2016. 180 fl. Dissertação (Mestrado) - Programa de Pós-Graduação em Comunicação, Universidade de Brasília, Brasília, 2016. Disponível em: http://repositorio.unb.br/handle/10482/21525. Acesso em: 25 maio 2019.

KOSSA, Pablo. Caminhos para a comunicação pública: a rádio universitária como estudo de caso. 2010. 125 fl. Dissertação (Mestrado) - Programa de Pós-Graduação em Comunicação, Universidade Federal de Goiás, Goiânia, 2010. Disponível em: https://bit.ly/2EulrV5. Acesso em: 26 maio 2019.

MILANEZ, Liana. Rádio MEC: herança de um sonho. Rio de Janeiro: ACERP, 2007.

MOREIRA, Sônia Virgínia. O Rádio no Brasil. Rio de Janeiro: Rio Fundo Editora, 1991. 
MULlER, Thomas Antonio Correia. Diretrizes da Rádio UFT FM. Palmas: Universidade Federal do Tocantins, 2017. Disponível em: http://docs.uft.edu.br/share/s/14ckJZyZQD6ASdT2Yd1WHw. Acesso em: 13 maio 2018.

NEUBERGER, Rachel Severo Alves. O rádio na era da convergência das mídias. Cruz das Almas: UFRB, 2012.

PIMENTEL, Fábio Prado. O rádio educativo no Brasil: uma visão histórica. 2. ed. Rio de Janeiro: SOARMEC Editora, 2009.

PRATA, Nair. Panorama do rádio em Belo Horizonte. In: PRATA, Nair (org). O rádio entre as montanhas - histórias, teorias e afetos da radiofonia mineira. Belo Horizonte: Editora Fundac, 2010.

RÁDIO DA UNIVERSIDADE. Nossa História. Porto Alegre, [S.d.]. Disponível em: http://www.radio.ufrgs.br/radio.html. Acesso em: 26 maio 2019.

REDE DE RÁDIOS UNIVERSITÁRIAS DO BRASIL. Manifesto pela criação da Rede de Rádios Universitárias do Brasil. [mensagem pessoal]. Mensagem recebida por: rfmedeiros13@gmail.com em 16 nov. 2017.

TAVARES, Reynaldo C. Histórias que o rádio não contou: do galena ao digital, desvendando a radiodifusão no Brasil e no mundo. São Paulo: Negócio Editora, 1997.

VIEIRA, Allana Meirelles; COUTINHO, Iluska Maria da Silva. Participação e autonomia relativa no Conselho Curador da EBC. Revista Comunicação e Sociedade, Braga, v. 30, p. 187-204, 2016. Disponível em: http://revistacomsoc.pt/index.php/comsoc/article/view/2493. Acesso em: 25 maio 2019.

ZUCULOTO, Valci Regina Mousquer. As tendências do rádio na globalização e sob o impacto das novas tecnologias: a experiência da Rede Universitária de Rádio como exemplo de busca de espaço e função. In: Congresso Brasileiro de Ciências da Comunicação, 19, 1996. Londrina. Anais [...] São Paulo: Intercom, 1996. Disponível em: https://bit.ly/2QmDdOP. Acesso em: 24 maio 2019.

ZUCULOTO, Valci Regina Mousquer. A programação das rádios públicas brasileiras. Florianópolis: Insular, 2012.

Submetido em: 24.10.2018

Aprovado em: 03.05.2019 